\title{
Sex differences in tumor characteristics, treatment, and outcomes of gastric and esophageal cancer surgery: nationwide cohort data from the Dutch Upper GI Cancer Audit
}

\author{
Marianne C. Kalff ${ }^{1}(1) \cdot$ Anna D. Wagner ${ }^{2} \cdot$ Rob H. A. Verhoeven ${ }^{3,4}$. Valery E. P. P. Lemmens $s^{3,5}$. \\ Hanneke W. M. van Laarhoven ${ }^{4}$. Suzanne S. Gisbertz ${ }^{1} \cdot$ Mark I. van Berge Henegouwen $^{1}$ on behalf of the Dutch \\ Upper GI Cancer Audit group
}

Received: 18 January 2021 / Accepted: 27 July 2021 / Published online: 7 August 2021

(c) The Author(s) 2021

\begin{abstract}
Background Sex differences in clinicopathological characteristics, treatment, and postoperative outcomes of gastric and esophageal cancer are largely undefined. This study aimed to compare tumor and treatment characteristics and outcomes of gastric and esophageal cancer surgery between male and female patients.

Methods Patients after elective surgery for primary esophageal (EAC) or gastric adenocarcinoma (GAC) registered in the Dutch Upper GI Cancer Audit between 2011 and 2016 were included. The primary endpoint, 5-year relative survival with relative excess risk (RER), i.e., adjusted for the normal life expectancy, was compared between male and female patients with EAC and GAC.

Results In total, 4937 patients were included (75\% male) with a mean age of 66 years. cT and cN-stages showed a similar distribution in male and female patients. In females, antrum GAC was more frequent ( $47 \%$ vs. $38 \%, p<0.001)$. Female patients with EAC less frequently received neo-adjuvant treatment $(\mathrm{OR}=0.60,95 \% \mathrm{CI} 0.38-0.96, p=0.033)$. For GAC, less postoperative morbidity (33\% vs. $38 \% p=0.017)$ and less re-interventions $(12 \%$ vs. $16 \%, p=0.008)$ were observed in females, although they had inferior 5-year relative survival (49\% vs. 56\%, RER $=1.31,95 \%$ CI $1.09-1.58, p=0.004)$. No differences in relative survival of EAC were observed.

Conclusions In addition to significant sex differences in tumor location, female patients with esophageal adenocarcinoma less frequently received neo-adjuvant therapy, and female patients with gastric adenocarcinoma had inferior relative survival. Further consideration and exploration of sex differences in surgical treatment and outcomes are necessary to improve tailored treatment and outcomes.
\end{abstract}

Keywords Gastric cancer · Esophageal cancer · Gastrectomy · Esophagectomy · Survival

Marianne C. Kalff

m.c.kalff@amsterdamumc.nl

$\triangle$ Mark I. van Berge Henegouwen

m.i.vanbergehenegouwen@amsterdamumc.nl

1 Department of Surgery, Cancer Center Amsterdam, Amsterdam UMC, University of Amsterdam, Amsterdam, the Netherlands

2 Department of Oncology, Lausanne University Hospital (CHUV), University of Lausanne (UNIL), Lausanne, Switzerland
3 Department of Research, Netherlands Comprehensive Cancer Organization (IKNL), Utrecht, the Netherlands

4 Department of Medical Oncology, Cancer Center Amsterdam, Amsterdam UMC, University of Amsterdam, Amsterdam, the Netherlands

5 Department of Public Health, Erasmus University Medical Centre, Rotterdam, the Netherlands 


\section{Introduction}

The incidence of gastric and esophageal cancer is substantially higher in male patients $[1,2]$. For both gastric and esophageal adenocarcinomas, behavioral risk factors, such as obesity or exposure to carcinogens like tobacco smoking, do not entirely explain the sex disparity in incidence seen across multiple populations [3-5], thus strongly suggesting sex differences in susceptibility and/or biology for this type of cancer. In fact, increasing evidence suggests a sexual dimorphism in cancer biology, and sex-biased molecular signatures have been observed across multiple tumor types [6-10].

Perioperative chemotherapy and neo-adjuvant chemoradiotherapy combined with surgical resection are the mainstays of curative treatment for gastric and esophageal cancer, respectively [11, 12]. While the impact of the patients' sex on the balance between efficacy and toxicity of systemic treatments in oncology has gained more attention in recent years [13, 14], its impact on surgical outcomes has been investigated less frequently. Previous studies have shown that for both gastric and esophageal cancer, male patients more frequently undergo surgery $[15,16]$. Furthermore, in gastric cancer patients treated exclusively with gastrectomy, the Dutch D1D2-trial showed a superior survival in female patients after an extended (D2) lymphadenectomy [17]. In addition, the CROSS-trial, evaluating the benefit of neo-adjuvant chemoradiotherapy versus surgery alone for esophageal cancer, portrayed a more pronounced treatment effect in males [18].

As a result of the difference in incidence, only relatively small absolute numbers of female patients are included in many clinical trials concerning gastric and esophageal cancer treatment, impeding any firm conclusions concerning the magnitude of the treatment benefit in female patients. In the context of the limited data, the aim of this study was to examine sex differences in tumor and treatment characteristics, and outcomes of gastric and esophageal cancer surgery in a large nationwide cohort study, to provide ground for further individualization of gastric and esophageal cancer treatment.

\section{Materials and methods}

Data for this study were acquired from the national Dutch Upper GI Cancer Audit (DUCA) database. In the Netherlands, caregivers are obliged to register all patients with gastric and esophageal cancer with intended resection in the DUCA registry. This audit is part of the Dutch Institute for Clinical Auditing (DICA), and was initiated in 2011 with the aim of providing independent information on the quality of care. Validation of case completeness (99.8\%) and accuracy (94-100\%) has been performed [19, 20]. Data registration for audit purposes is limited to 30 days after surgery, or when extending over 30 days, the duration of the initial hospital stay. To allow research initiatives regarding survival, DUCA-data were linked with data of the Dutch national health care insurance registry (Vektis). As health care insurance is mandatory for all Dutch inhabitants, this registry includes $99 \%$ of the Dutch population. Date of death is registered given that insurance ends as the patient dies. The process of matching datasets and subsequent validation has been described recently [21]. Data collected from the combined dataset consisted of baseline patient characteristics, tumor and treatment specifications, and histopathological and postoperative outcomes, and vital status.

This study was approved by the scientific committee of the DUCA. No informed consent, opt-out procedure, or ethical approval was required under Dutch law. This paper complies with the STROBE guidelines for observational cohort studies [22].

\section{Patients and treatment}

All patients with a primary esophageal or gastric adenocarcinoma that underwent a surgical procedure with curative intent between 2011 and 2016 were retrieved from the DUCA dataset. Patients with missing information on sex, and patients that underwent a salvage or non-elective procedure were excluded. All patients underwent surgery with curative intent and remained in the analyses if, due to unforeseen circumstances (e.g., metastatic disease and tumor extent), no surgical resection was performed. The performed surgical procedures were a transthoracic or transhiatal esophagectomy, a total or partial gastrectomy, or no resection (i.e., bypass or surgical exploration). Multimodal treatment regimens consisted of neo-adjuvant or perioperative treatment (combined neo-adjuvant and adjuvant treatment).

\section{Outcome data and definitions}

The primary outcome was 5-year relative survival after gastric and esophageal cancer surgery. Secondary outcomes were differences in tumor characteristics, treatment specifications, short-term morbidity and mortality, and oncological outcomes such as response to neo-adjuvant treatment. Relative survival was defined as the observed overall survival divided by the age, year, and sex-matched expected overall survival of the general Dutch population [23]. Clinical and pathological TNM staging was defined by the eighth TNM staging edition. Survival was calculated as the interval (in months) from the date of surgery to the date of death or last follow-up (Vektis database last follow-up: 1st of September 2017). 


\section{Statistical analysis}

For all outcomes investigated, stratification was performed by tumor location in esophageal and gastric adenocarcinoma. Primary and secondary endpoints were subsequently compared between male and female patients. Mann-Whitney $U$ or Student's $t$ test for continuous variables, and $\chi^{2}$ test for categorical variables were used when applicable.

In case of treatment differences between male and female patients, regarding the application of neo-adjuvant or perioperative treatment, transhiatal or transthoracic esophagectomy for esophageal tumors, and partial or total gastrectomy for gastric tumors, additional multivariable logistic regression analysis was performed to assess whether differences remained after adjustment for clinical parameters thought to affect treatment probability (age, ASA-class, the presence of cardiac, pulmonary, vascular or diabetic comorbidities, clinical $\mathrm{T}$ and $\mathrm{N}$ stage, tumor differentiation, histopathological subtype, tumor location, and year of surgery), resulting in odds ratios (OR) with $95 \%$ confidence intervals $(95 \% \mathrm{CI})$.

As the general life expectancy is known to differ between sexes, relative survival was assessed as the overall survival observed in the gastric and esophageal cancer patient cohort, divided by the expected survival in the general Dutch population matched on age, sex, and year, according to the method of Pohar Perme [23]. To assess the association between sex and risk of death, multivariable relative excess risk (RER) with $95 \%$ CI was estimated using the relative survival, adjusted for confounders known to affect survival (age, ASA-score, clinical T and N stage, and tumor sub-location).

Fig. 1 Flowchart of study inclusion. *Multiple reasons for exclusion may apply for one patient
As pre-menopausal female sex hormones, i.e., estrogen, are thought to have a protective effect reducing the risk and invasiveness of gastric and esophageal adenocarcinoma, subgroup analyses comparing male patients to female patients $\leq 55$ and $>55$ years were performed [6, 24-27].

Few missing data were present in clinical variables and therefore handled by complete case analyses. STATA Version 14.2 (StataCorp, College Station, TX, USA) was used to assess relative survival, and SPSS Statistics Version 26.0 (Armonk, NY) was used for further statistical analysis. Twosided $p$ values of less than 0.05 were considered statistically significant.

\section{Results}

\section{Baseline characteristics}

In total, 2865 patients with esophageal and 2072 patients with gastric adenocarcinoma were included, of whom $74.8 \%$ were male (Fig. 1; Table 1). More cardiac comorbidities were observed in male patients in both groups. No sex differences were observed in the distribution of clinical $\mathrm{T}$ and $\mathrm{N}$ stage. For gastric adenocarcinoma, more poorly differentiated tumors and more diffuse type tumors were observed in females ( $69.4 \%$ vs. $56.5 \%, p<0.001 ; 48.6 \%$ vs. $34.9 \%, p<0.001$, respectively), who also had tumors more frequently located in the antrum (46.7\% vs. $37.5 \%)$, while males more often had tumors located in the fundus $(10.9 \%$ vs. $5.0 \%, p<0.001$; Fig. 2).

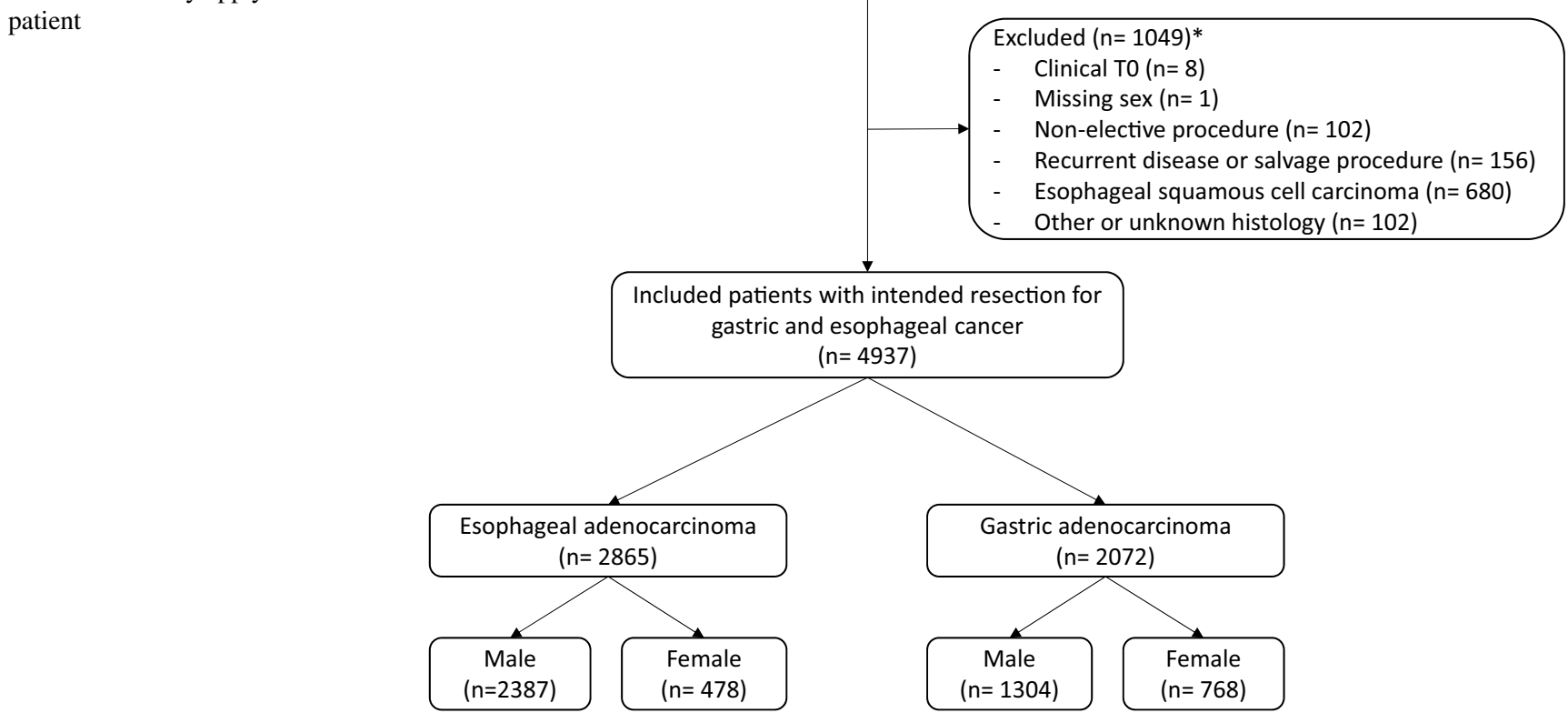


Table 1 Baseline characteristics of male and female patients with gastric and esophageal cancer

\begin{tabular}{|c|c|c|c|c|c|c|c|c|c|c|c|}
\hline \multirow[t]{4}{*}{ Characteristics } & & \multicolumn{5}{|c|}{ Esophageal cancer } & \multicolumn{5}{|c|}{ Gastric cancer } \\
\hline & & \multirow{2}{*}{\multicolumn{2}{|c|}{$\begin{array}{l}\text { Male } \\
n=2387\end{array}$}} & \multirow{2}{*}{\multicolumn{2}{|c|}{$\frac{\text { Female }}{n=478}$}} & \multirow[t]{3}{*}{$p$} & \multirow{2}{*}{\multicolumn{2}{|c|}{$\begin{array}{l}\text { Male } \\
n=1304\end{array}$}} & \multirow{2}{*}{\multicolumn{2}{|c|}{$\frac{\text { Female }}{n=768}$}} & \multirow[t]{3}{*}{$p$} \\
\hline & & & & & & & & & & & \\
\hline & & $n$ & $\%$ & $n$ & $\%$ & & $n$ & $\%$ & $n$ & $\%$ & \\
\hline Mean age & Years (SD) & 64.6 & 9.1 & 65.0 & 9.3 & 0.454 & 68.6 & 11.0 & 67.7 & 12.9 & 0.115 \\
\hline Age $\leq 55$ year & & 372 & 15.6 & 75 & 15.7 & 0.959 & 158 & 12.1 & 146 & 19.0 & $<0.001$ \\
\hline Mean BMI & $\mathrm{Kg} / \mathrm{m}^{2}(\mathrm{SD})$ & 26.4 & 4.0 & 26.8 & 5.6 & 0.114 & 25.3 & 4.1 & 25.1 & 4.9 & 0.197 \\
\hline \multirow[t]{4}{*}{ ASA score } & I & 416 & 17.6 & 71 & 15.1 & 0.515 & 170 & 13.2 & 123 & 16.3 & 0.209 \\
\hline & II & 1422 & 60.1 & 285 & 60.5 & & 726 & 56.2 & 422 & 55.8 & \\
\hline & III & 519 & 21.9 & 112 & 23.8 & & 385 & 29.8 & 206 & 27.2 & \\
\hline & IV & 11 & 0.5 & 3 & 0.6 & & 11 & 0.9 & 5 & 0.7 & \\
\hline \multirow[t]{4}{*}{ Comorbidity } & Pulmonary & 418 & 17.5 & 87 & 18.2 & 0.703 & 244 & 18.7 & 91 & 11.9 & $<0.001$ \\
\hline & Cardiac & 617 & 25.8 & 89 & 18.7 & 0.001 & 449 & 34.4 & 177 & 23.1 & $<0.001$ \\
\hline & Vascular & 886 & 37.1 & 203 & 42.6 & 0.025 & 522 & 40.0 & 283 & 37.0 & 0.171 \\
\hline & Diabetes & 402 & 16.8 & 82 & 17.2 & 0.852 & 217 & 16.6 & 123 & 16.1 & 0.739 \\
\hline \multirow[t]{5}{*}{ cT stage } & Tis & 9 & 0.4 & - & & 0.076 & 7 & 0.7 & 3 & 0.5 & 0.363 \\
\hline & $\mathrm{T} 1$ & 115 & 5.1 & 37 & 8.1 & & 76 & 8.0 & 57 & 10.4 & \\
\hline & $\mathrm{T} 2$ & 445 & 19.6 & 86 & 18.8 & & 252 & 26.3 & 133 & 24.2 & \\
\hline & $\mathrm{T} 3$ & 1644 & 72.2 & 321 & 70.2 & & 541 & 57.0 & 305 & 55.6 & \\
\hline & $\mathrm{T} 4$ & 63 & 2.8 & 13 & 2.8 & & 73 & 7.7 & 51 & 9.3 & \\
\hline \multirow[t]{5}{*}{$\mathrm{cN}$ stage } & No & 829 & 36.0 & 195 & 42.5 & 0.115 & 648 & 58.1 & 378 & 57.6 & 0.927 \\
\hline & $\mathrm{N} 1$ & 951 & 41.3 & 170 & 37.0 & & 303 & 27.2 & 176 & 26.8 & \\
\hline & N2 & 427 & 18.6 & 75 & 16.3 & & 108 & 9.7 & 63 & 9.6 & \\
\hline & $\mathrm{N} 3$ & 68 & 3.0 & 15 & 3.3 & & 15 & 1.3 & 12 & 1.8 & \\
\hline & $\mathrm{N}+$ & 26 & 1.1 & 4 & 0.9 & & 41 & 3.7 & 27 & 4.1 & \\
\hline \multirow[t]{2}{*}{ Differentiation } & Good & 866 & 55.2 & 163 & 51.7 & 0.267 & 437 & 43.5 & 178 & 30.6 & $<0.001$ \\
\hline & Poor & 704 & 44.8 & 152 & 48.3 & & 567 & 56.5 & 404 & 69.4 & \\
\hline \multirow[t]{3}{*}{ Histological subtype } & Intestinal & 788 & 81.2 & 160 & 82.1 & 0.562 & 515 & 57.7 & 239 & 45.0 & $<0.001$ \\
\hline & Diffuse & 116 & 12.0 & 19 & 9.7 & & 311 & 34.9 & 258 & 48.6 & \\
\hline & Mixed & 66 & 6.8 & 16 & 8.2 & & 66 & 7.4 & 34 & 6.4 & \\
\hline \multirow[t]{8}{*}{ Clinical tumor location } & Cervical & 2 & 0.1 & - & - & 0.597 & & & & & \\
\hline & Proximal & 4 & 0.2 & 2 & 0.4 & & & & & & \\
\hline & Middle & 81 & 3.4 & 21 & 4.4 & & & & & & \\
\hline & Distal & 1527 & 64.4 & 301 & 63.1 & & & & & & \\
\hline & GEJ & 757 & 31.9 & 153 & 32.1 & & & & & & \\
\hline & Fundus & & & & & & 136 & 10.9 & 37 & 5.0 & $<0.001$ \\
\hline & Corpus & & & & & & 389 & 31.2 & 232 & 31.7 & \\
\hline & Antrum & & & & & & 468 & 37.5 & 342 & 46.7 & \\
\hline \multirow{3}{*}{$\begin{array}{l}\text { Belongs to tumor loca- } \\
\text { tion }\end{array}$} & Pylorus & & & & & & 104 & 8.3 & 64 & 8.7 & \\
\hline & Entire stomach & & & & & & 73 & 5.8 & 53 & 7.2 & \\
\hline & Gastric remnant & & & & & & 78 & 6.3 & 5 & 0.7 & \\
\hline
\end{tabular}

Percentages for the variables are calculated out of the total number of actual results available, excluding the missing values. Percentages may not add up to $100 \%$ due to rounding

ASA American Society of Anesthesiologists, $B M I$ body mass index $\left(\mathrm{kg} / \mathrm{m}^{2}\right), c N$ clinical N stage, $c T$ clinical T stage, $G E J$ gastro-esophageal junction, $S D$ standard deviation

\section{Treatment characteristics}

Females with esophageal adenocarcinoma less often received neo-adjuvant treatment ( $78.1 \%$ vs. $85.6 \%$; OR $0.60,95 \%$ CI $0.38-0.96, p=0.033$; Table 2), which less often consisted of chemoradiotherapy compared to neo-adjuvant treatment 


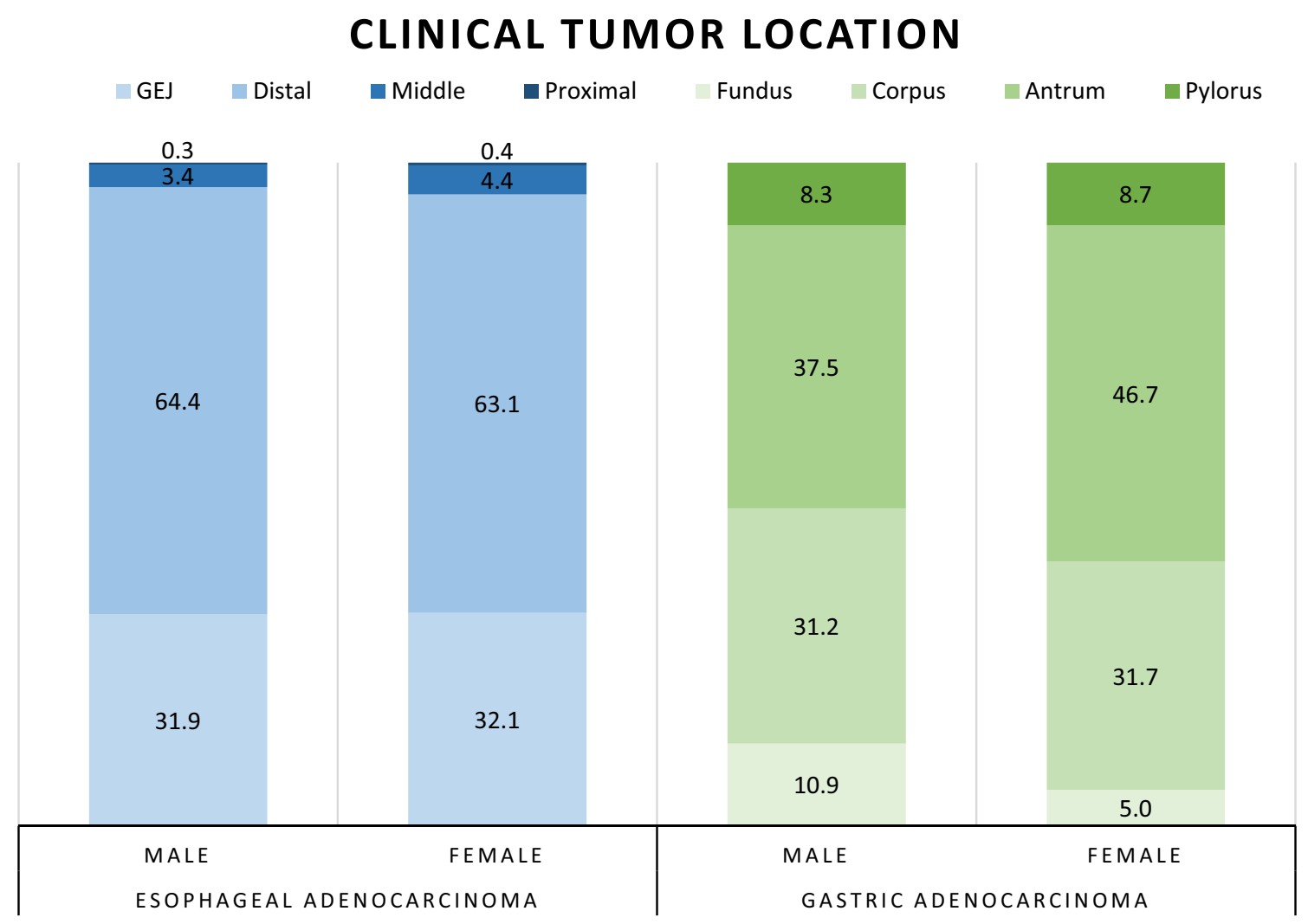

Fig. 2 Distribution of tumor location and histology for male and female patients with gastric and esophageal cancer. Numbers represent the percentages of tumor location for male and female patients. GEJ gastro-esophageal junction

regimens in male patients $(90.5 \%$ vs. $93.9 \%, p=0.019)$. Less females with gastric adenocarcinoma received perioperative treatment ( $35.2 \%$ vs. $40.3 \%, p=0.024)$, although not significant when adjusted for clinicopathological factors (OR 0.75, 95\% CI 0.52-1.06, $p=0.105$ ).

For both esophageal and gastric adenocarcinoma, the type of surgical procedure performed differed. For esophageal adenocarcinoma, more female patients underwent a transhiatal resection $(42.3 \%$ vs. $36.8 \%, p<0.001)$, and for gastric adenocarcinoma, more female patients underwent a partial gastrectomy $(55.8 \%$ vs. $48.8 \%, p=0.007)$. These differences did not remain significant after adjustment for clinicopathological factors (EAC: OR 0.73, 95\% CI 0.50-1.08, $p=0.119$; GAC: OR $1.23,95 \%$ CI $0.83-1.81, p=0.300$ ). No sex difference was observed for open or minimally invasive approaches.

\section{Postoperative and histopathological outcomes}

A microscopically radical resection (R0) was equally obtained in both sexes (Table 3). Pathological T stage differed for patients with gastric adenocarcinoma, with lower pT stages in female patients (pT3: $37.0 \%$ vs. $41.8 \%$, $p=0.014)$. $\mathrm{pN}$ stage differed between male and female patients with esophageal adenocarcinoma, while (positive) lymph-node harvest showed no difference. The responses to neo-adjuvant therapy were equally distributed. Only for patients with gastric adenocarcinoma, postoperative morbidity differed; with more complications in general (38.1\% vs. $32.9 \%, p=0.017)$, more pulmonary complications $(15.7$ vs. $10.8 \%, p=0.002)$, more anastomotic leakages $(7.5 \%$ vs. $5.1 \%, p=0.031)$, and more re-interventions $(16.2 \%$ vs. $11.9 \%, p=0.008)$ in male patients. Postoperative morbidity was higher after total versus partial gastrectomy $(41.9 \%$ vs. $34.4 \%, p=0.001)$. Short-term mortality was comparable between male and female patients in both groups.

\section{Survival}

For females with gastric cancer, 5-year relative survival was inferior to male patients ( $48.6 \%$ vs. $55.8 \%$ ), also when adjusted for clinicopathological factors (RER 1.31, 95\% CI $1.09-1.58, p=0.004)$. No statistically significant differences in 5-year relative survival were observed between male and female patients with esophageal adenocarcinoma (52.4\% vs. 54.2\%; RER 1.01, 95\% CI 0.86-1.19, $p=0.891$; Fig. 3). 
Table 2 Treatment characteristics of male and female patients with gastric and esophageal cancer

\begin{tabular}{|c|c|c|c|c|c|c|c|c|c|c|c|}
\hline \multirow[t]{4}{*}{ Characteristics } & & \multicolumn{5}{|c|}{ Esophageal cancer } & \multicolumn{5}{|c|}{ Gastric cancer } \\
\hline & & \multirow{2}{*}{\multicolumn{2}{|c|}{$\begin{array}{l}\text { Male } \\
n=2387\end{array}$}} & \multirow{2}{*}{\multicolumn{2}{|c|}{$\begin{array}{l}\text { Female } \\
n=478\end{array}$}} & \multirow[t]{3}{*}{$p$} & \multirow{2}{*}{\multicolumn{2}{|c|}{$\begin{array}{l}\text { Male } \\
n=1304\end{array}$}} & \multirow{2}{*}{\multicolumn{2}{|c|}{$\frac{\text { Female }}{n=768}$}} & \multirow[t]{3}{*}{$p$} \\
\hline & & & & & & & & & & & \\
\hline & & $n$ & $\%$ & $n$ & $\%$ & & $n$ & $\%$ & $n$ & $\%$ & \\
\hline \multirow[t]{4}{*}{ Neo-adjuvant treatment } & & 2033 & 85.6 & 370 & 78.1 & $<0.001$ & 298 & 23.0 & 165 & 21.6 & 0.463 \\
\hline & Chemotherapy & 125 & 6.1 & 35 & 9.5 & 0.019 & 275 & 92.3 & 159 & 96.4 & 0.083 \\
\hline & CRT & 1908 & 93.9 & 335 & 90.5 & & 23 & 7.7 & 6 & 3.6 & \\
\hline & $>80 \%$ completed & 1948 & 96.8 & 351 & 95.9 & 0.396 & 200 & 67.2 & 110 & 67.5 & 0.956 \\
\hline Perioperative treatment ${ }^{\mathrm{a}}$ & & 133 & 5.6 & 34 & 7.1 & 0.188 & 499 & 40.3 & 260 & 35.2 & 0.024 \\
\hline \multirow[t]{5}{*}{ Procedure type } & Transthoracic & 1357 & 57.0 & 234 & 49.3 & $<0.001$ & 10 & 0.8 & 1 & 0.1 & 0.007 \\
\hline & Transhiatal & 876 & 36.8 & 201 & 42.3 & & 13 & 1.0 & 4 & 0.5 & \\
\hline & Total gastrectomy & 62 & 2.6 & 11 & 2.3 & & 531 & 41.1 & 267 & 35.0 & \\
\hline & Partial gastrectomy & 2 & 0.1 & 4 & 0.8 & & 631 & 48.8 & 425 & 55.8 & \\
\hline & No resection ${ }^{\mathrm{b}}$ & 84 & 3.5 & 25 & 5.3 & & 107 & 8.3 & 65 & 8.5 & \\
\hline \multirow[t]{3}{*}{ Approach of surgery } & Open & 1087 & 45.6 & 230 & 48.1 & 0.448 & 932 & 71.9 & 528 & 69.4 & 0.222 \\
\hline & MIS & 1251 & 52.5 & 242 & 50.6 & & 364 & 28.1 & 233 & 30.6 & \\
\hline & Hybrid & 44 & 1.8 & 6 & 1.3 & & NA & & NA & & \\
\hline \multirow[t]{5}{*}{ Year of surgery } & 2011 & 412 & 17.3 & 87 & 18.2 & 0.247 & 193 & 14.8 & 103 & 13.4 & 0.377 \\
\hline & 2012 & 444 & 18.6 & 105 & 22.0 & & 213 & 16.3 & 144 & 18.8 & \\
\hline & 2013 & 459 & 19.2 & 94 & 19.7 & & 286 & 21.9 & 181 & 23.6 & \\
\hline & 2014 & 514 & 21.5 & 99 & 20.7 & & 342 & 26.2 & 181 & 23.6 & \\
\hline & 2015 & 558 & 23.4 & 93 & 19.5 & & 270 & 20.7 & 159 & 20.7 & \\
\hline
\end{tabular}

Percentages for the variables are calculated out of the total number of actual results available, excluding the missing values. Percentages may not add up to $100 \%$ due to rounding

CRT chemoradiotherapy, MIS minimally invasive surgery, NA not applicable

${ }^{\mathrm{a}}$ Consisting of both neo-adjuvant and adjuvant treatment

${ }^{\mathrm{b}}$ Surgery for intended curative resection, due to metastatic disease, tumor extent, or deterioration of the condition of the patient during surgery, no surgical resection was performed

\section{Subgroup analysis}

While the mean age at diagnosis was comparable between sexes, gastric cancer patients $\leq 55$ years were more frequently of female sex $(19.0 \%$ vs. $12.1 \%, p<0.001)$. Young female gastric cancer patients were more frequently diagnosed with poor tumor differentiation $(84.3 \%$ vs. $68.0 \%$, $p=0.004)$, and diffuse-type tumors $(72.5 \%$ vs. $50.4 \%$, $p=0.004$ ) compared to males (Online Resource 1). For older female gastric cancer patients, percentages of poor differentiation $(66.0 \%$ vs. $56.5 \%, p<0.001)$ and diffuse subtype $(42.9 \%$ vs. $34.9 \%, p=0.018)$ remained significantly higher compared to males, although the inter-sex difference was less pronounced.

For both female esophageal cancer patients $\leq 55$ and $>55$ years, relative survival was comparable to male patients (Online Resource 2), while for female gastric cancer patients, relative survival was inferior to males, especially for those $\leq 55$ years (RER $1.41,95 \%$ CI $1.03-1.94$, $p=0.033$ ).

\section{Discussion}

While increasing evidence suggests an impact of the patients' sex on the balance between efficacy and toxicity of systemic treatments in oncology $[13,14]$, its impact on surgical treatment choices and outcomes for gastric and esophageal cancers is largely undefined. In this context, our study reveals several major findings. In addition to sex differences in tumor location and histology of gastric cancer, a superior relative survival was observed in male patients, despite a higher postoperative morbidity rate. In contrast, while the use of neo-adjuvant treatment differs significantly between male and female esophageal cancer patients, postoperative morbidity and 5-year relative survival were comparable.

Specifically, in female gastric cancer patients, tumors were more often located in the antrum, while in male patients, tumors were more frequently located in the gastric fundus. No sex differences were observed in tumor location for esophageal adenocarcinoma, while in the literature, a more proximal esophageal tumor location has 
Table 3 Pathological and postoperative outcomes of male and female patients with gastric and esophageal cancer

\begin{tabular}{|c|c|c|c|c|c|c|c|c|c|c|c|}
\hline \multirow[t]{4}{*}{ Characteristics } & & \multicolumn{5}{|c|}{ Esophageal cancer } & \multicolumn{5}{|c|}{ Gastric cancer } \\
\hline & & \multirow{2}{*}{\multicolumn{2}{|c|}{$\begin{array}{l}\text { Male } \\
n=2387\end{array}$}} & \multirow{2}{*}{\multicolumn{2}{|c|}{$\frac{\text { Female }}{n=478}$}} & \multirow[t]{3}{*}{$p$} & \multirow{2}{*}{\multicolumn{2}{|c|}{$\begin{array}{l}\text { Male } \\
n=1304\end{array}$}} & \multirow{2}{*}{\multicolumn{2}{|c|}{$\frac{\text { Female }}{n=768}$}} & \multirow[t]{3}{*}{$p$} \\
\hline & & & & & & & & & & & \\
\hline & & $n$ & $\%$ & $n$ & $\%$ & & $n$ & $\%$ & $n$ & $\%$ & \\
\hline \multirow[t]{2}{*}{ Lymph nodes, median (IQR) } & Number & 18 & $13-24$ & 17 & $12-24$ & 0.636 & 18 & $13-26$ & 19 & $13-28$ & 0.069 \\
\hline & Positive & 0 & $0-2$ & 0 & $0-2$ & 0.185 & 1 & $0-5$ & 1 & $0-5$ & 0.717 \\
\hline \multirow[t]{6}{*}{ (y)pT stage } & T0 & 373 & 16.9 & 73 & 16.9 & 0.815 & 67 & 5.7 & 25 & 3.6 & 0.014 \\
\hline & Tis & 23 & 1.0 & 6 & 1.4 & & 13 & 1.1 & 6 & 0.9 & \\
\hline & $\mathrm{T} 1$ & 396 & 17.9 & 85 & 19.6 & & 161 & 13.8 & 130 & 18.8 & \\
\hline & $\mathrm{T} 2$ & 450 & 20.3 & 79 & 18.2 & & 184 & 15.7 & 117 & 16.9 & \\
\hline & $\mathrm{T} 3$ & 935 & 42.3 & 185 & 42.7 & & 489 & 41.8 & 256 & 37.0 & \\
\hline & $\mathrm{T} 4$ & 35 & 1.6 & 5 & 1.2 & & 256 & 21.9 & 158 & 22.8 & \\
\hline \multirow[t]{4}{*}{ (y)pN stage } & N0 & 1322 & 57.7 & 280 & 62.2 & 0.005 & 538 & 45.4 & 320 & 46.1 & 0.486 \\
\hline & N1 & 474 & 20.7 & 64 & 14.2 & & 218 & 18.4 & 122 & 17.6 & \\
\hline & $\mathrm{N} 2$ & 307 & 13.4 & 75 & 16.7 & & 207 & 17.5 & 107 & 15.4 & \\
\hline & N3 & 188 & 8.2 & 31 & 6.9 & & 221 & 18.7 & 145 & 20.9 & \\
\hline \multirow[t]{2}{*}{ (y)pM stage } & M0 & 2192 & 98.3 & 429 & 98.2 & 0.800 & 1049 & 93.9 & 616 & 94.2 & 0.812 \\
\hline & M1 & 37 & 1.7 & 8 & 1.8 & & 68 & 6.1 & 38 & 5.8 & \\
\hline \multirow[t]{2}{*}{ Resection } & R0 & 2139 & 93.7 & 413 & 93.2 & 0.714 & 1032 & 88.6 & 595 & 87.9 & 0.654 \\
\hline & $\mathrm{R}+$ & 144 & 6.3 & 30 & 6.8 & & 133 & 11.4 & 82 & 12.1 & \\
\hline \multirow[t]{3}{*}{ Response to neo-adjuvant treatment } & None & 231 & 12.9 & 55 & 16.3 & 0.239 & 187 & 36.1 & 108 & 37.9 & 0.065 \\
\hline & Partial & 1214 & 67.6 & 219 & 64.8 & & 272 & 52.5 & 159 & 55.8 & \\
\hline & Complete & 352 & 19.6 & 64 & 18.9 & & 59 & 11.4 & 18 & 6.3 & \\
\hline \multirow[t]{4}{*}{ Postoperative complication } & Yes & 1350 & 56.7 & 273 & 57.2 & 0.845 & 496 & 38.1 & 252 & 32.9 & 0.017 \\
\hline & Leakage & 444 & 18.7 & 76 & 15.9 & 0.333 & 98 & 7.5 & 39 & 5.1 & 0.031 \\
\hline & Pulmonary & 686 & 28.8 & 144 & 30.2 & 0.553 & 205 & 15.7 & 83 & 10.8 & 0.002 \\
\hline & Cardiac & 289 & 12.1 & 57 & 11.9 & 0.904 & 78 & 6.0 & 35 & 4.6 & 0.169 \\
\hline \multicolumn{2}{|l|}{ Re-intervention } & 505 & 21.4 & 103 & 21.6 & 0.907 & 209 & 16.2 & 91 & 11.9 & 0.008 \\
\hline \multicolumn{2}{|l|}{ Median ICU stay (IQR) } & 2 & $1-4$ & 2 & $1-5$ & 0.618 & 0 & $0-1$ & 0 & $0-1$ & 0.135 \\
\hline \multicolumn{2}{|l|}{ Median LOS (IQR) } & 12 & 9-19 & 13 & 9-19 & 0.026 & 9 & $7-14$ & 9 & $7-13$ & 0.970 \\
\hline \multicolumn{2}{|l|}{ Short-term mortality ${ }^{a}$} & 79 & 3.4 & 18 & 3.9 & 0.579 & 74 & 5.8 & 33 & 4.4 & 0.172 \\
\hline
\end{tabular}

Percentages for the variables are calculated out of the total number of actual results available, excluding the missing values. Percentages may not add up to $100 \%$ due to rounding

$I C U$ intensive-care unit, $I Q R$ interquartile range, $L O S$ length of stay, $p N$ pathological $\mathrm{N}$ stage, $p T$ pathological $\mathrm{T}$ stage, $p M$ pathological $\mathrm{M}$ stage

${ }^{\text {a }}$ Short-term mortality is the combined 30-day and in-hospital mortality

been described in female patients [28, 29]. In line with the previous studies, we observed more poorly differentiated and diffuse-type gastric cancers in female patients [30]. As much as histologic and molecular subtypes are distributed according to a characteristic pattern within the stomach and esophagus [31-33], these cancers seem to be distributed in a characteristic pattern for male and female patients, reflecting a "sexual dimorphism" most likely related to biological sex differences in cancer susceptibility and tumor biology [34].

Furthermore, significant differences in treatment allocation were observed in the current study. Even when adjusted for age, ASA-class, the presence of comorbidities, clinical stage, tumor differentiation, histopathological subtype, tumor location, and year of surgery, females with esophageal adenocarcinoma were significantly less frequently treated with neo-adjuvant therapy. No rational explanation for this treatment gap could be identified based on relevant clinicopathological factors, implicating that other factors must contribute. Potentially, unconscious gender bias in medical decisions, as described for other diseases, might play a role [35-38]. In addition, female patients less often received chemotherapy with concurrent radiotherapy as neo-adjuvant regimen. This observation is consistent with the recent study of Nobel et al. [28], in which they consider prior mediastinal irradiation for breast cancer as a possible explanation for the less frequent administration of concurrent radiotherapy. 


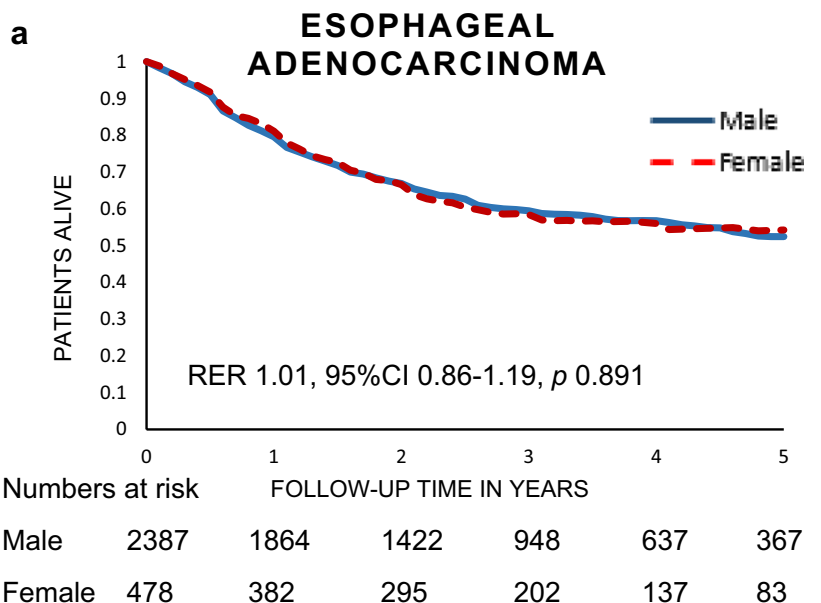

b GASTRIC ADENOCARCINOMA

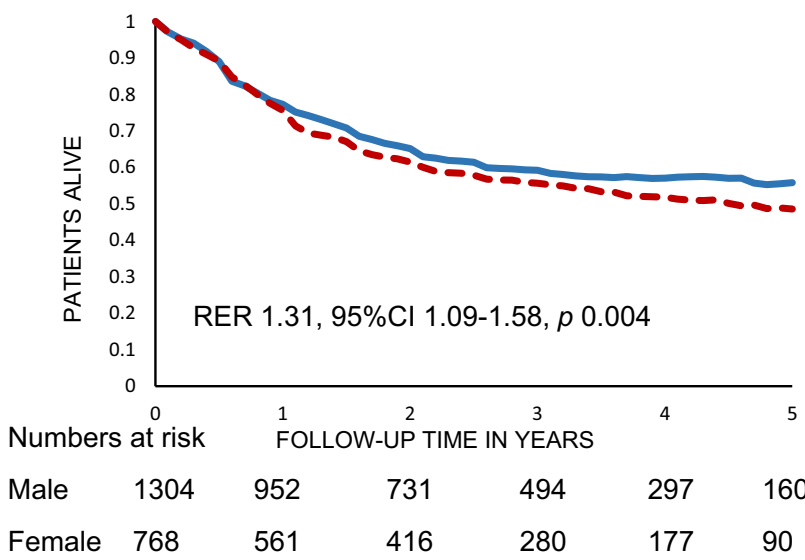

Fig. 3 Relative survival of male and female patients with esophageal and gastric adenocarcinoma. a Relative survival of male and female patients with esophageal adenocarcinoma. b Relative survival of male and female patients with gastric adenocarcinoma. RER relative excess risk

Within the DUCA registry, more females had a history of malignancy; however, as type of previous cancer and mediastinal irradiation is not registered, this hypothesis could not be confirmed. Although the previous studies on chemotherapy in gastric and esophageal cancer treatment observed more toxicity in female patients, resulting in less cycles of chemotherapy [14], the current study found no difference in the percentage of patients who completed neo-adjuvant therapy.

Only for patients with gastric cancer, postoperative morbidity and re-intervention rate differed between the sexes; with more complications and more re-interventions in male patients. The higher incidence of postoperative morbidity in male patients might be explained by a higher incidence of pre-operative comorbidity and a more extensive surgical procedure, with more males undergoing a total gastrectomy in the current study $[39,40]$. Of interest, the higher incidence of anastomotic leakage in male patients with gastric cancer is also frequently observed after surgery of the lower gastro-intestinal tract, with male patients at higher risk for anastomotic leakage [41, 42].

Rates of incomplete tumor removal were comparable between sexes with gastric and esophageal cancer, although higher after gastric cancer surgery. While this is in line with the literature, incomplete tumor removal negatively impacts prognosis and is associated with low annual hospital volumes, emphasizing the need for further centralization of surgical gastric cancer care [43, 44].

Since life expectancy is known to differ between male and female patients, we chose to correct this by estimating and comparing the relative survival according to the method described by Pohar Perme [23]. No significant differences in 5-year relative survival were observed between male and female patients with esophageal adenocarcinoma, portraying similar survival of both sexes with esophageal cancer allocated to surgical treatment. While this comparable survival is in line with the previous studies [28, 29], they did not take differences in life expectancy into account.

In contrast, for gastric cancer, a superior relative survival was observed in male patients. Considering the prognostic favorable lower rate of comorbidities and postoperative morbidity [21], as well as the lower pathological $\mathrm{T}$ stages and more distal tumor locations observed in female patients [45, 46], the inferior survival of female gastric cancer patients might be explained by differences in tumor biology, such as the higher rate of poorly differentiated and diffuse-type tumors in females, which counterbalances the favorable impact of lower comorbidities, postoperative morbidity, pathological $\mathrm{T}$ stage, and tumor location. This observation is consistent with others; both Dutch [47] and Norwegian [48] population-based studies demonstrated higher proportions of diffuse-type gastric cancer in female patients and a significantly poorer survival for diffuse-type cancer. Furthermore, this observation does not seem to be limited to Caucasians; a large retrospective Korean study [30] confirms the higher rate of undifferentiated and diffuse-type gastric tumors in female patients and their negative prognostic impact.

Moreover, sex differences are potentially modulated by age [38] and might be the result of differences in exposure to sex hormones [6, 24, 25]. In the current study, especially young female gastric cancer patients were diagnosed with poor tumor differentiation and diffuse-type tumors, and showed inferior relative survival compared to males, which is consistent with the literature [30,49]. Although a protective effect of female (pre-menopausal) sex hormones is hypothesized, the current study observed more female gastric cancer patients aged $\leq 55$ years, with more prognostic negative tumor characteristics and a poorer relative survival. As a consequence of the observed sex differences in tumor biology and prognosis, sex-specific multimodal treatment 
strategies merit consideration and investigation in clinical trials.

There were some limitations to the present study. Although the validation of the matched DUCA-Vektis dataset was not published until November 2019 [21], the matching was already performed in September 2017. Since no additional update was performed, more recent data could not be included in this study. Another limitation to this combined dataset is the error margin up to $6 \%$, caused by the incorrect assumption of death when health care insurance was terminated, e.g., in case of emigration [21]. However, there is no reason to assume that this error affected male and female patients differently and subsequently affected the results of our study. Due to the purpose of this registry, we were not able to include patients allocated to non-surgical treatment strategies, such as definitive chemoradiotherapy. Therefore, we cannot exclude that the observed differences might be due to a different allocation of male and female patients to surgical treatment. Additionally, due to the anonymous character of the DUCA dataset, we were not able to include other variables of interest, such as socio-economic status, which might affect access to care and treatment allocation, toxicity, or a possible discrepancy between treatment advised by the multidisciplinary team and actual treatment chosen.

Future research should include all patients diagnosed with gastric and esophageal cancer, regardless of treatment, to enable further investigation of sex differences in tumor characteristics, treatment allocation, and subsequent outcomes.

In conclusion, this study clearly demonstrates statistically significant and clinically relevant sex differences in tumor characteristics, treatment allocation, postoperative morbidity, and survival among surgically treated patients with gastric and esophageal cancer. As such, it provides an illustrative example of how sex and gender modulate surgical risks and outcomes. While the observed differences in gastric cancer histology are most likely related to biological sex differences in cancer susceptibility and tumor biology, also referred to as "sexual dimorphism" in cancer, differences in patient or tumor characteristics do not explain the observed treatment gap between male and female patients with esophageal adenocarcinoma, which might be attributable to other factors, such as unconscious gender bias. Consequently, the consideration of sex and gender differences in surgical research and treatment decisions is necessary and considered as an important step toward the individualization of gastric and esophageal cancer treatment.

Supplementary Information The online version contains supplementary material available at https://doi.org/10.1007/s10120-021-01225-1.

Acknowledgements The authors would like to thank all surgeons, registrars, physician assistants, and administrative nurses for data registration in the DUCA database, as well as the Dutch Upper GI Cancer Audit group for scientific input.

Funding No funding was received for this study.

\section{Declarations}

Conflict of interest Wagner has received consulting fees from BMS, Servier Suisse, Merck, MSD, Bayer, EMD Serono, Lilly, Celgene, Shire, and Pfizer, non-financial support (for congress participations) from Sanofi, Astra-Zeneca, AbbVIE, and Ipsen, and an educational grant from Roche to EORTC. Verhoeven has received unrestricted research grants from BMS and Roche. Van Laarhoven has served as a consultant for BMS, Celgene, Lilly, Merck, Nordic, and Servier, and has received unrestricted research funding from Bayer, BMS, Celgene, Lilly, Merck Serono, MSD, Nordic, Philips, Roche, and Servier. Van Berge Henegouwen reports research grants from Olympus and Stryker, in addition to consulting fees from Medtronic, Mylan, and Johnson and Johnson. Lemmens has received unrestricted research grants and educational grants from Roche. The remaining authors have no conflict of interest to report.

Open Access This article is licensed under a Creative Commons Attribution 4.0 International License, which permits use, sharing, adaptation, distribution and reproduction in any medium or format, as long as you give appropriate credit to the original author(s) and the source, provide a link to the Creative Commons licence, and indicate if changes were made. The images or other third party material in this article are included in the article's Creative Commons licence, unless indicated otherwise in a credit line to the material. If material is not included in the article's Creative Commons licence and your intended use is not permitted by statutory regulation or exceeds the permitted use, you will need to obtain permission directly from the copyright holder. To view a copy of this licence, visit http://creativecommons.org/licenses/by/4.0/.

\section{References}

1. Arnold M, Soerjomataram I, Ferlay J, Forman D. Global incidence of oesophageal cancer by histological subtype in 2012. Gut. 2015;64(3):381-7.

2. Khazaei S, Rezaeian S, Soheylizad M, Khazaei S, Biderafsh A. Global incidence and mortality rates of stomach cancer and the human development index: an ecological study. Asian Pac J Cancer Prev. 2016;17(4):1701-4.

3. Coleman HG, Xie SH, Lagergren J. The epidemiology of esophageal adenocarcinoma. Gastroenterology. 2018;154(2):390-405.

4. Freedman ND, Derakhshan MH, Abnet CC, Schatzkin A, Hollenbeck AR, McColl KEL. Male predominance of upper gastrointestinal adenocarcinoma cannot be explained by differences in tobacco smoking in men versus women. Eur J Cancer. 2010;46(13):2473-8.

5. Rutegård $\mathrm{M}$, Nordenstedt $\mathrm{H}, \mathrm{Lu} \mathrm{Y}$, Lagergren $\mathrm{J}$, Lagergren $\mathrm{P}$. Sex-specific exposure prevalence of established risk factors for oesophageal adenocarcinoma. Br J Cancer. 2010;103(5):735-40.

6. Clocchiatti A, Cora E, Zhang Y, Dotto GP. Sexual dimorphism in cancer. Nat Rev Cancer. 2016;16(5):330-9.

7. Yuan Y, Liu L, Chen H, Wang Y, Xu Y, Mao H, et al. Comprehensive characterization of molecular differences in cancer between male and female patients. Cancer Cell. 2016;29(5):711-22.

8. Abancens M, Bustos V, Harvey H, McBryan J, Harvey BJ. Sexual dimorphism in colon cancer. Front Oncol. 2020;10(December):1-27. 
9. Li CH, Prokopec SD, Sun RX, Yousif F, Schmitz N, Al-Shahrour $F$, et al. Sex differences in oncogenic mutational processes. Nat Commun. 2020;11(1):1-24.

10. Rubin JB, Lagas JS, Broestl L, Sponagel J, Rockwell N, Rhee $\mathrm{G}$, et al. Sex differences in cancer mechanisms. Biol Sex Differ. 2020;11(1):1-29.

11. Van Hagen P, Hulshof MCCM, Van Lanschot JJB, Steyerberg EW, Van Berge Henegouwen MI, Wijnhoven BPL, et al. Preoperative chemoradiotherapy for esophageal or junctional cancer. N Engl J Med. 2012;366(22):2074-84.

12. Cunningham D, Allum W, Stenning S, Thompson J, Van de Velde C, Nicolson M, et al. Perioperative chemotherapy versus surgery alone for resectable gastroesophageal cancer. N Engl J Med. 2006;355(1):11-20.

13. Özdemir BC, Csajka C, Dotto GP, Wagner AD. Sex differences in efficacy and toxicity of systemic treatments: an undervalued issue in the era of precision oncology. J Clin Oncol. 2018;36(26):2680-3.

14. Davidson M, Wagner AD, Kouvelakis K, Nanji H, Starling N, Chau I, et al. Influence of sex on chemotherapy efficacy and toxicity in oesophagogastric cancer: a pooled analysis of four randomised trials. Eur J Cancer. 2019;121:40-7.

15. Van Putten M, Verhoeven RHA, Van Sandick JW, Plukker JTM, Lemmens VEPP, Wijnhoven BPL, et al. Hospital of diagnosis and probability of having surgical treatment for resectable gastric cancer. Br J Surg. 2016;103(3):233-41.

16. Van Putten M, Koëter M, Van Laarhoven HWM, Lemmens VEPP, Siersema PD, Hulshof MCCM, et al. Hospital of diagnosis influences the probability of receiving curative treatment for esophageal cancer. Ann Surg. 2018;267(2):303-10.

17. Songun I, Putter H, Kranenbarg EMK, Sasako M, van de Velde CJH. Surgical treatment of gastric cancer: 15-year follow-up results of the randomised nationwide Dutch D1D2 trial. Lancet Oncol. 2010;11(5):439-49.

18. Shapiro J, van Lanschot JJB, Hulshof MCCM, van Hagen P, van Berge Henegouwen MI, Wijnhoven BPL, et al. Neoadjuvant chemoradiotherapy plus surgery versus surgery alone for oesophageal or junctional cancer (CROSS): long-term results of a randomised controlled trial. Lancet Oncol. 2015;16(9):1090-8.

19. Busweiler LAD, Wijnhoven BPL, van Berge Henegouwen MI, Henneman D, van Grieken NCT, Wouters MWJM, et al. Early outcomes from the Dutch upper gastrointestinal cancer audit. $\mathrm{Br}$ J Surg. 2016;103(13):1855-63.

20. van der Werf LR, Voeten SC, van Loe CMM, Karthaus EG, Wouters MWJM, Prins HA. Data verification of nationwide clinical quality registries. BJS Open. 2019;3:857-64.

21. Van Der Werf LR, Wijnhoven BPL, Fransen LFC, Van Sandick JW, Nieuwenhuijzen GAP, Busweiler LAD, et al. A national cohort study evaluating the association between short-term outcomes and long-term survival after esophageal and gastric cancer surgery. Ann Surg. 2019;270(5):868.

22. von Elm E, Altman DG, Egger M, Pocock SJ, Gøtzsche PC, Vandenbroucke JP. The strengthening the reporting of observational studies in epidemiology (STROBE) statement: guidelines for reporting observational studies. Int J Surg. 2014;12(12):1495-9.

23. Perme MP, Henderson R, Stare J. An approach to estimation in relative survival regression. Biostatistics. 2009;10(1):136-46.

24. Camargo MC, Goto Y, Zabaleta J, Morgan DR, Correa P, Rabkin CS. Sex hormones, hormonal interventions, and gastric cancer risk: a meta-analysis. Cancer Epidemiol Biomark Prev. 2012;21(1):20-38

25. Lagergren K, Lagergren J, Brusselaers N. Hormone replacement therapy and oral contraceptives and risk of oesophageal adenocarcinoma: a systematic review and meta-analysis. Int J Cancer. 2014;135(9):2183-90.
26. Bohanes P, Yang D, Chhibar RS, Labonte MJ, Winder T, Ning Y, et al. Influence of sex on the survival of patients with esophageal cancer. J Clin Oncol. 2012;30(18):2265-72.

27. Ryu W-S, Kim J-H, Jang Y-J, Park S-S, Um J-W, Park S-H, et al. Expression of estrogen receptors in gastric cancer andtheir clinical significance. J Surg Oncol. 2012;106(4):456-61.

28. Nobel TB, Livschitz J, Eljalby M, Janjigian YY, Bains MS, Adusumilli PS, et al. Unique considerations for females undergoing esophagectomy. Ann Surg. 2019;272(1):1.

29. Morita M, Otsu H, Kawano H, Kasagi Y, Kimura Y, Saeki H, et al. Gender differences in prognosis after esophagectomy for esophageal cancer. Surg Today. 2014;44(3):505-12.

30. Kim HW, Kim JH, Lim BJ, Kim HK, Kim H, Park JJ, et al. Sex disparity in gastric cancer: female sex is a poor prognostic factor for advanced gastric cancer. Ann Surg Oncol. 2016;23(13):4344-51.

31. Bass AJ, Thorsson V, Shmulevich I, Reynolds SM, Miller M, Bernard B, et al. Comprehensive molecular characterization of gastric adenocarcinoma. Nature. 2014;513(7517):202-9.

32. Kim J, Bowlby R, Mungall AJ, Robertson AG, Odze RD, Cherniack $\mathrm{AD}$, et al. Integrated genomic characterization of oesophageal carcinoma. Nature. 2017;541(7636):169-74.

33. Rice TW, Ishwaran H, Blackstone EH. Oesophageal cancer: location, location, location. Eur J Cardio-thoracic Surg. 2015;48(2):194-5.

34. Mauvais-Jarvis F, Bairey Merz N, Barnes PJ, Brinton RD, Carrero JJ, DeMeo DL, et al. Sex and gender: modifiers of health, disease, and medicine. Lancet. 2020;396(10250):565-82.

35. McMurray RJ, Clarke OW, Barrasso JA, Clohan DB, Epps CH, Glasson J, et al. Gender disparities in clinical decision making. JAMA J Am Med Assoc. 1991;266(4):559-62.

36. Biddle C, Fallavollita JA, Homish GG, Orom H. Gender bias in clinical decision making emerges when patients with coronary heart disease symptoms also have psychological symptoms. Hear Lung. 2019;48(4):331-8.

37. Levin N, Mor M, Ben-Hur T. Patterns of misdiagnosis of multiple sclerosis. Isr Med Assoc J. 2003;5(7):489-90.

38. Wagner AD, Oertelt-Prigione S, Adjei A, Buclin T, Cristina V, Csajka C, et al. Gender medicine and oncology: report and consensus of an ESMO workshop. Ann Oncol. 2019;30(12):1914-24.

39. Wright CD, Kucharczuk JC, O'Brien SM, Grab JD, Allen MS. Predictors of major morbidity and mortality after esophagectomy for esophageal cancer: a society of thoracic surgeons general thoracic surgery database risk adjustment model. J Thorac Cardiovasc Surg. 2009;137(3):587-96.

40. Papenfuss WA, Kukar M, Oxenberg J, Attwood K, Nurkin S, Malhotra U, et al. Morbidity and mortality associated with gastrectomy for gastric cancer. Ann Surg Oncol. 2014;21(9):3008-14.

41. Lipska MA, Bissett IP, Parry BR, Merrie AEH. Anastomotic leakage after lower gastrointestinal anastomosis: men are at a higher risk. ANZ J Surg. 2006;76(7):579-85.

42. Rullier E, Laurent C, Garrelon JL, Michel P, Saric J, Parneix M. Risk factors for anastomotic leakage after rectal cancer surgery. Br J Surg. 1998;85(3):355-8.

43. Wang SY, Yeh CN, Lee HL, Liu YY, Chao TC, Hwang TL, et al. Clinical impact of positive surgical margin status on gastric cancer patients undergoing gastrectomy. Ann Surg Oncol. 2009;16(10):2738-43.

44. van der Werf LR, Cords C, Arntz I, Belt EJT, Cherepanin IM, Coene PPLO, et al. Population-based study on risk factors for tumor-positive resection margins in patients with gastric cancer. Ann Surg Oncol. 2019;26(7):2222-33.

45. Deng J, Chu X, Ren Z, Wang B. Relationship between T stage and survival in distantly metastatic esophageal cancer: A STROBEcompliant study. Medicine (Baltimore). 2020;99(19):e20064. 
46. Yu X, Hu F, Li C, Yao Q, Zhang H, Xue Y. Clinicopathologic characteristics and prognosis of proximal and distal gastric cancer. Onco Targets Ther. 2018;11:1037-44.

47. van der Kaaij RT, Koemans WJ, van Putten M, Snaebjornsson P, Luijten JCHBM, van Dieren JM, et al. A population-based study on intestinal and diffuse type adenocarcinoma of the oesophagus and stomach in the Netherlands between 1989 and 2015. Eur J Cancer. 2020;130:23-31.

48. Bringeland EA, Wasmuth HH, Mjønes P, Myklebust T, Grønbech JE. A population-based study on incidence rates, Lauren distribution, stage distribution, treatment, and long-term outcomes for gastric adenocarcinoma in Central Norway 2001-2011. Acta Oncol (Madr). 2017;56(1):39-45.
49. Dijksterhuis WPM, Kalff MC, Wagner AD, Verhoeven RHA, Lemmens VEPP, van Oijen MGH, et al. (2021) Gender Differences in Treatment Allocation and Survival of Advanced Gastroesophageal Cancer: a Population-Based Study. J Natl Cancer Inst. 2021. https://doi.org/10.1093/jnci/djab075.

Publisher's Note Springer Nature remains neutral with regard to jurisdictional claims in published maps and institutional affiliations. 